\title{
Sources of Agricultural Information Used by Arable Crop Farmers in Isale Osun Farm Settlement, Osogbo Local Government Area of Osun State
}

\author{
A. E. Agwu* and A. A. Adeniran \\ Department of Agricultural Extension \\ University of Nigeria, Nsukka \\ *Corresponding author's e-mail:agwuekwe1@yahoo.com
}

\begin{abstract}
The study ascertained the sources of agricultural information used by arable crop farmers in Isale Osun farm settlement, Osogbo local government area of Osun State. Data were collected from 80 respondents through the use of structured interview schedule and analyzed using percentages, mean scores and bivalent correlation analysis. The findings revealed that farmers received their agricultural information mostly through mediated and professional inter-personal channels/methods. The findings further showed that radio $(\bar{x}=3.40)$ and fellow farmers $(\bar{x}=3.40)$ were the most perceived appropriate channels for disseminating agricultural information as reported by the farmers. However, the result of the study showed that extension agents $(\bar{x}=3.37)$, radio $(\bar{x}=3.34)$ and television $(\bar{x}=3.16)$ were the most reliable channels for communicating agricultural information to farmers. The results of the bivalent correlation analysis showed positive significant relationships between educational attainment and use of professional information sources; farmers' age and use of various information sources as well as household size and use of professional mass media sources $(P<0.05)$. However, level of illiteracy $(\bar{x}=3.97)$, unavailability of information sources $(\bar{x}=3.94)$, lack of access to information sources $(\bar{x}=$ 3.93) and inappropriate scheduling of programmes $(\bar{x}=3.89)$ were the most serious problems associated with receiving information through the different communication sources. The study therefore recommended that government should assist farmers in the area by sponsoring adult education so that farmers can make best use of the different agricultural information sources effectively. It also points to the need for the provision of enabling environment for such facilities as the internet to thrive in rural areas.
\end{abstract}

\section{INTRODUCTION}

Human race is totally dependent on agriculture and as the world population continues to grow, there must be continuous reassessment of agricultural practices to optimize their efficiency (Mugabe, 2003). In many parts of the developed world such as Europe and the United States of America (USA), agriculture is a highly efficient industry and continues to demonstrate annual increase in productivity. In contrast, many developing countries are still not self sufficient in food production due to many reasons such as lack of good agricultural practices, hostile climate, or 
political instability. Many developing societies are intrinsically poor and lack the ability to take advantage of new technologies hence they suffer from food crisis situation.

According to Yahaya and Olajide (2000) the diffusion and adoption of innovations remains the back bone of the expected development in agriculture. Olowu (1998) noted that development and production of relevant and appropriate technologies is one of the pre-requisites for sustainable agricultural production. Others include dissemination of these technologies as well as their eventual utilization. Nigerian government has addressed the issue of development of appropriate technologies through the establishment of research institutes and creation of universities of technologies and agriculture.

Over the years, the national and international research institutes have 'churned out' numerous publications that are usually intended for extension agents and farmers (Patel and Anthonio, 1971). It is now evident from all the Research-Extension-Farmers-Inputs-Linkage System (REFILS) workshops being organized in each of the country's agricultural zones, that research institutes with mandate of different crops have over time accumulated a lot of technologies for improving agricultural practices in the country (Omokhude, 1999).

Extension services are essentially communicative. It has therefore been recommended that extension should forge communication link to create network for sharing knowledge and experience (World Bank, 1990), since the purpose of communication is to bring about change of attitude, knowledge, skills and aspiration of the receivers (Agwu et. al., 2008). According to Ekumankama (2000), sustainable agricultural development will continue to elude Nigeria unless appropriate innovations are effectively communicated to the farming population.

Communication plays a major role in human development especially in agriculture. Communication includes those situation in which a source transmits a message to a receiver with conscious intent to affect the latter's behaviour. It is a vital part of personal life and also important in different fields such as business, education, agriculture, rural development and other situations where people encounter each other. Unlike message sending, communication requires response of others. There must be sharing of meaning for effective communication to take place (Baron, 2002). According to Ekumankma and Nwankwo (2002), the poor exposure of farmers to appropriate agricultural information is one of the major reasons for low yield recorded by many Nigerian farmers. This has been of great concern to agricultural communicators, administrators and policy makers in the country over the years. This study therefore sought to ascertain the sources of agricultural information used by the arable crop farmers in Isale Osun farm settlement, Osogbo Local Government Area of Osun State, Nigeria.

\section{Purpose of the study}

The general purpose of this study is to ascertain the sources of agricultural information used by the arable crop farmers in Isale Osun Farm Settlement, Osogbo Local Government Area of Osun State.

The specific objectives include to:

1. ascertain farmers' reported sources of information on improved arable crop technologies;

2. determine farmers' perceived appropriateness of the various information channels to their needs;

3. ascertain the opinion of the farmers regarding the reliability of the various sources in communicating information on arable crop production and 


\section{Journal of Agricultural Extension}

Vol. 13 (1) June, 2009

4. ascertain farmers reported problems associated with receiving information on new technologies through the different communication sources.

The study tested the following null hypothesis:

$\mathrm{HO}$ : There is no significant relationship between socio-economic characteristics (age, number of years spent on formal education, household size and farming experience) of farmers and their use of various information sources.

\section{METHODOLOGY}

The population for the study consists of about 350 small holder farmers (cultivating less than 6 hectares of farm land yearly often in two or more separate parcels) who reside in the settlement called "Isale Osun Farm settlement of Osun State. Simple random sampling technique was used in selecting 80 respondents from the settlement who were interviewed for this study. Data were collected from the respondents through the use of semi- structured interview schedule. To ascertain farmers' reported sources of information on improved arable crops production, a list of information sources was presented to the respondents with response options of "yes" and "no" to indicate which of the sources were major sources of information on new technologies relating to arable crops. To ascertain the appropriateness of the various disseminating channels, a fourpoint Likert-type scale with options ranging from "not appropriate", "fairly appropriate", "appropriate", and "very appropriate" and scaled 1 to 4 respectively was used. To ascertain the opinion of the farmers regarding the reliability of the various sources of information in communicating new information on arable crops, a four- point Likert-type scale of "not reliable", "fairly reliable", "reliable" and "very reliable", scaled 1 to 4 were used. However, the problems associated with communicating new technologies vis-à-vis the different channels, was measured on a three-point Likert-type scale ranging from "not serious", "serious" to "very serious" scaled 1 to 3 .

Responses of the four-point and three point scales were later categorized according to their mean scores using the methodology of Anyanwu et. al., (2002). In terms of reliability of information sources, sources of information with means scores of 2.5 or above were classified as more reliable sources, while those with mean scores of below 2.5 were regarded as less reliable sources of information. Also, information sources with mean scores of 2.5 or above were regarded as appropriate sources while those with mean scores of below 2.5 were regarded as inappropriate sources. In terms of respondents' perception of problems associated with communicating new technologies through the different channels, problems with mean scores of 2 or above were classified as serious problems while those with mean scores of less than 2.0 not being serious in relation to communication of agricultural information to farmers visà-vis the different channels.

All the objectives were analysed using percentages, mean scores and standard deviations, while bivalent correlation analysis was used to determine the degree of relationships between socio-economic characteristics (age, number of years spent on formal education, household size and farming experience) of farmers and their use of various information sources. Statistical package for Social Sciences (SPSS) constituted the software package used for the analysis. 


\section{RESULTS AND DISCUSSION}

\section{Farmers' reported methods used by extension workers for disseminating information on improved arable crop technologies}

Table 1 shows that farm and home visit (91.3\%); method demonstration (91.3\%), radio (88.0\%), opinion leaders $(82.5 \%)$, talk show $(77.5 \%)$ telephone calls and posters $(70 \%$ each) and text messages $(52.5 \%)$ were major sources of information used by extension workers for disseminating information on improved crop technologies to farmers. Film and slide show presentation, books and leaflets $(23.8 \%$ each), exhibition $(22 \%)$, news papers $(20 \%)$, magazines $(16.3 \%)$ extension bulletin $(18 \%)$, television, talk show, internet, and electronic mail $(10 \%, 7.5 \%, 3.8 \%$ and $2.5 \%$ respectively) were identified by few of the respondents as the methods used by the extension agents in disseminating information in the area. The data show that most farmers received their farm information through mediated and professional interpersonal methods.

The implication here is that interpersonal and group methods were perceived as the most frequent methods used by the extension agents in disseminating agricultural information to farmers, probably because of the possibilities of immediate feed back and multiplier effects of these methods. An earlier study by Anyanwu et al (2002) reported that women farmers in Orumba North LGA of Anambra state received their farm information from non-professional inter-personal sources more often than from mediated and professional inter-personal sources. However, Mohammed and Wanaso (1993) pointed out that the choice of communication channels is to a large extent a factor of farmer's circumstances. The fact that Electronic mail and the Internet were the least channels of disseminating information to the farmer's points to the need for having an enabling environment for such modern Information Communication Technologies to thrive in the area. According to Agwu and Chah (2007) the Internet is a formidable source of information; and information on recent developments in the field of agricultural extension can be readily obtained from the Internet. 
Journal of Agricultural Extension

Vol. 13 (1) June, 2009

TABLE 1: Farmers' reported methods used by extension workers for disseminating information on arable crop technologies

\begin{tabular}{lcc}
\hline Methods used & \multicolumn{2}{c}{ Percentage of Farmers } \\
& Yes & No \\
\hline Radio & 88.00 & 12.00 \\
Television & 10.00 & 90.00 \\
Newspapers & 20.00 & 80.00 \\
Extension bulletin & 18.80 & 81.00 \\
Telephone calls & 70.00 & 30.00 \\
Posters/Bill board & 76.00 & 23.80 \\
Exhibition & 22.50 & 77.50 \\
Talking drum & 7.50 & 92.50 \\
Electronic mail & 2.50 & 97.50 \\
Internet & 3.80 & 96.30 \\
Text messages & 52.50 & 47.50 \\
Film/slide presentation & 23.80 & 76.30 \\
Leaflets & 23.80 & 76.30 \\
Magazines & 16.30 & 83.80 \\
Talk shows & 77.50 & 22.50 \\
Opinion leaders & 82.50 & 17.50 \\
Farm/Home visits & 91.30 & 8.80 \\
Method demonstration & 91.30 & 8.80 \\
Result demonstration & 87.50 & 12.50 \\
\hline
\end{tabular}

Journal of Agricultural Extension

Vol. $13(2), 2009$

\section{Appropriateness of the Various Disseminating Channels of Information}

The result of the responses of the farmers as regard appropriateness of the various disseminating channels is shown in Table 2. The Table revealed that the most appropriate channel as perceived by the farmers was radio $(\bar{x}=3.40)$. Omenesa (1997) had earlier observed that radio programmes are usually timely and capable of extending messages to the audience no matter where they may be as long as they have a receiver with adequate supply of power. He further asserted that such obstacles as absence of road, light and water are no hindrance to radio as well as illiteracy since messages can be passed in the audience own language. Fellow farmers $(\bar{x}=3.40)$, extension agents $(\bar{x}=3.15)$ and television $(\bar{x}=3.08)$ were also perceived as appropriate sources with high mean scores. The fact that they indicated radio, fellow farmers and extension agents among the most appropriate channels may be as a result of the wide coverage of radio, the multiplier effects of fellow farmers in disseminating agricultural information and interpersonal interactions of the farmers as well as the fact that messages from extension agents most often enhance adoption of innovations.

Others perceived appropriate sources include public awareness campaign $(\bar{x}=2.95)$, posters and bills $(\bar{x}=2.94)$, friends and neighbours $(\bar{x}=2.89)$, extension bulletins $(\bar{x}=2.80)$, exhibitions $(\bar{x}=2.80)$, books /leaflets/magazines $(\bar{x}=2.79)$, women cooperative societies ( $\bar{x}=2.74)$, opinion leaders $(\bar{x}=2.69)$, telephone calls $(\bar{x}=2.69)$, text messages $(\bar{x}=2.54)$, news papers $(\bar{x}=2.50)$ and drama $(\bar{x}=2.50)$. 
However, the respondents did not perceive electronic mail $(\bar{x}=2.39)$, internet $(\bar{x}=2.30)$ and researchers $(\bar{x}=2.02)$ as appropriate means of disseminating information on arable crops to them. The non- availability of e-mail and internet facilities in this area may have accounted for farmers' perceived non-appropriateness of these channels, which further points to the need for these facilities in the rural areas.

TABLE 2: Mean scores of farmers' opinions on the appropriateness of the various disseminating channels

\begin{tabular}{lll}
\hline Sources of Information & Mean $(\bar{x})$ & Standard Deviation \\
\hline Radio & $3.40^{*}$ & 0.704 \\
Television & $3.08^{*}$ & 0.978 \\
Newspapers & $2.50^{*}$ & 0.810 \\
Extension bulletin & $2.80^{*}$ & 0.991 \\
Telephone calls & $2.68^{*}$ & 0.833 \\
Posters/bill board & $2.94^{*}$ & 0.880 \\
Exhibition & $2.80^{*}$ & 0.830 \\
Electronic mails & 2.39 & 1.000 \\
Internet & 2.30 & 0.610 \\
Text messages & $2.54^{*}$ & 0.980 \\
Film/slide presentation & $2.05^{*}$ & 0.520 \\
Books/leaflets/magazines & $2.79^{*}$ & 0.807 \\
Opinion leaders & $2.68^{*}$ & 0.883 \\
Friends and neighbours & $2.89^{*}$ & 0.711 \\
Fellow farmers & $3.40^{*}$ & 0.704 \\
Women cooperative society & $2.74^{*}$ & 0.725 \\
Public campaign & $2.95^{*}$ & 0.825 \\
Drama & $3.15^{*}$ & 0.811 \\
Extension agents & $2.50^{*}$ & 0.781 \\
Researchers & 2.02 & 0.480 \\
\hline
\end{tabular}

* Appropriate

\section{Reliability of Various Channels of Information}

Table 3 shows that the farmers perceived extension agents $(\bar{x}=3.37)$, radio $(\bar{x}=3.34)$ and television $(\bar{x}=3.16)$, as the most reliable sources of information on farm matters. Also news papers $(\bar{x}=2.98)$, public campaign $(\bar{x}=2.95)$, opinion leaders $(\bar{x}=2.91)$, friends and neighbours $(\bar{x}=2.85)$, women cooperative societies $(\bar{x}=2.84)$, film/slide shows $(\bar{x}=2.81)$, bulletin $(\bar{x}=2.79)$, bill board/ posters $(\bar{x}=2.75)$, drama $(\bar{x}=2.71)$, telephone $(\bar{x}=2.58)$ and internet $(\bar{x}=2.50)$ were perceived as reliable sources of information by the farmers. Only electronic mail $(\bar{x}=2.39)$ and text message $(\bar{x}=2.45)$ were not found to be reliable channels of disseminating agricultural information. These findings show that respondents perceived extension agents and radio as sources of information that are most reliable. This therefore, calls for more commitment on the part of the extension agencies in their role of information dissemination activities. 
Journal of Agricultural Extension

Vol. 13 (1) June, 2009

TABLE 3: Mean scores of farmers' opinion of reliability of the various disseminating channels

\begin{tabular}{lll}
\hline Sources of Information & Mean $(\bar{x})$ & Standard Deviation \\
\hline Radio & $3.34^{*}$ & 0.665 \\
Television & $3.16^{*}$ & 0.863 \\
Newspapers & $2.98^{*}$ & 0.900 \\
Extension bulletin & $2.79^{*}$ & 0.837 \\
Telephone calls & $2.58^{*}$ & 0.952 \\
Posters/bill board & $2.75^{*}$ & 0.893 \\
Exhibition & $2.94^{*}$ & 0.946 \\
Electronic mails & 2.39 & 0.974 \\
Internet & 2.50 & 1.006 \\
Text messages & 2.45 & 0.992 \\
Film/slide presentation & $2.81^{*}$ & 0.887 \\
Books/leaflets/magazines & $2.73^{*}$ & 0.811 \\
Opinion leaders & $2.91^{*}$ & 0.732 \\
Friends and neighbours & $2.85^{*}$ & 0.797 \\
Fellow farmers & $3.03^{*}$ & 0.729 \\
Women cooperative society & $2.84^{*}$ & 0.737 \\
Public campaign & $2.95^{*}$ & 0.778 \\
Drama & $2.71^{*}$ & 0.994 \\
Extension agents & $3.37^{*}$ & 0.682 \\
Researchers & $3.26^{*}$ & 0.707 \\
\hline
\end{tabular}

* Reliable sources

Journal of Agricultural Extension

Vol. 13 (2), 2009

Farmers Perceived Problems associated with receiving Information through different Communication Sources

Results of the findings shown in Table 4 reveal that level of illiteracy $(\bar{x}=3.97)$, unavailability of information sources $(\bar{x}=3.94)$, lack of access to information sources $(x=3.93)$, and inappropriate scheduling of programmes $(\bar{x}=3.89)$ were perceived to be very serious problems associated with receiving information through the various communication sources. Also, problem of some local leaders withholding relevant information $(\bar{x}=2.96)$, language used in presentation of information ( $\bar{x}=2.91)$, inadequate technological content $(\bar{x}=2.83)$, innovation difficulty/complexity of understanding ( $\bar{x}=2.79)$, and insufficient contact with extension agents 
( $\bar{x}=2.73$ ) were also found to be serious problems. In addition, lack of money $(\bar{x}=2.65)$, safe keeping and retrieval of already disseminated information $(\bar{x}=2.65)$, problem of reliability of information sources $(\bar{x}=2.64)$, problem of gender bias on the use of information sources $(\bar{x}=2.59)$ and inability to ask question and get feed back $(\bar{x}=2.55)$ were identified as very serious problems, which need urgent attention for the improvement of agricultural productivity.

On the other hand, lack of access to current literature $(\bar{x}=1.95)$, irrelevant technological content $(\bar{x}=1.80)$, incompatibility of new knowledge with people's attitude, interest and belief $(\bar{x}=1.70)$, lack of interest $(\bar{x}=1.64)$ and lack of time to listen to agricultural information $(\bar{x}=1.56)$ were all perceived as not serious problems.

TABLE 4: Farmers perceived problems associated with receiving information on new technologies through different communication sources

\begin{tabular}{ll}
\hline Perceived problems & Means \\
\hline Language used in presentation of information & $2.91^{*}$ \\
Inability to ask question and quick few back & $2.55^{*}$ \\
Lack of time to listen to agricultural information & 1.56 \\
Innovation difficulty/complexity of understanding & 1.75 \\
Lack of interest & 1.64 \\
Lack of access to information sources & $3.93^{*}$ \\
Irrelevant content of technology & 1.80 \\
Inappropriate scheduling of programme & $3.98^{*}$ \\
Lack of money to acquire information source & $2.65^{*}$ \\
Inadequate technological content & $2.83^{*}$ \\
Unavailability of the information source & $3.94^{*}$ \\
Safekeeping and retrieval of already disseminated information & $2.64^{*}$ \\
Incompatibility of new knowledge with people's attitude, interest and belief & 1.70 \\
Illiteracy & $3.97^{*}$ \\
Problem of gender bias on the use of the information source & $2.59^{*}$ \\
Problem of reliability of information source & $2.64^{*}$ \\
Insufficiency content with extension agents & 2.73 \\
Lack of access to current literature & 1.95 \\
Problems of organisation leader withholding relevant information & $2.96^{*}$ \\
\hline
\end{tabular}

* Serious problems

\section{Relationships between selected Characteristics of Farmers and use of Various Information Sources}

The result of the bivalent correlation analysis in Table 5 showed that there was a positive, strong relationship $(p<0.05)$ between the age of the respondents and the use of information sources (newspapers, extension bulletins, posters, and bills, internet, books, magazines, methods demonstration, and results demonstration). This shows that as the farmers grow older, they tend to seek for more information from various sources.

Data in Table 5 also revealed that number of years spent on formal education by the respondents correlate positively and significantly $(P<0.05)$ with the use of extension bulletin, books, leaflets and magazines. According to Anyanwu et. al., (2002) educational attainment predisposes one to using different sources of information, emphasis being more on professional 
rather than inter personal sources of information. In other words, the more educated an individual, the more exposed the person becomes to sources of information. This finding is supported by Foo (1980) whose study indicated that more educated fathers and mothers tend to perceive general media sources as more useful.

Result of the analysis further showed that there was a positive significant relationship between house hold size and the use of professional mass methods of information dissemination (television, news papers, extension bulletin exhibition, talking drum, and film and slide presentations). The positive and significant correlation existing between the household and use of mass methods in disseminating information tends to suggest that the more the households, the more they sought information from professional mass media methods. Again, there was a positive and significant relationship $(P<0.05)$ between farming experience and the use of various professional information sources (newspapers, extension bulletin, posters and bills, exhibition, internet, books, magazines and results demonstration), suggesting that the more the farming experience of the farmer the more they sought information from professional sources.

TABLE 6: Relationships of some socioeconomic characteristics of farmers and their use of various information sources

\begin{tabular}{lcccc}
\hline $\begin{array}{l}\text { Information } \\
\text { Source }\end{array}$ & Age & $\begin{array}{c}\text { Number of years } \\
\text { spent on formal } \\
\text { Education }\end{array}$ & Household size & $\begin{array}{c}\text { Farming } \\
\text { Experience }\end{array}$ \\
\hline Interpersonal contact & $r .046$ & $r .170$ & $r .052$ & $r .022$ \\
Group contact & $r .092$ & $r-0.79$ & $r .216$ & $r-.062$ \\
Radio & $r-.071$ & $r .14$ & $r .002$ & $r-.177$ \\
Television & $r .204$ & $r-.120$ & $r .224^{*}$ & $r .209$ \\
Newspaper & $r .303^{*}$ & $r-.145$ & $r .292^{*}$ & $r .293^{*}$ \\
Extension bulletin & $r .460^{*}$ & $r .446^{*}$ & $r .283^{*}$ & $r .389^{*}$ \\
Telephone & $r-.109$ & $r-.034$ & $r .084$ & $r .003$ \\
Posters and bills & $r .253^{*}$ & $r-.114$ & $r .132$ & $r .253^{*}$ \\
Exhibition & $r .184$ & $r-.196$ & $r .250^{*}$ & $r .226^{*}$ \\
Talking drum & $r .008$ & $r-.0 .46$ & $r .241^{*}$ & $r .111$ \\
Electronic mail & $r .157$ & $r-.134$ & $r .052$ & $r .038$ \\
Internet & $r .309^{*}$ & $r-.047$ & $r .075$ & $r .232^{*}$ \\
Text messages & $r-.030$ & $r .071$ & $r-.019$ & $r .043$ \\
Film and slide presentation & $r .108$ & $r-.104$ & $r .257^{*}$ & $r .140$ \\
Books & $r .448^{*}$ & $r .376^{*}$ & $r .185$ & $r .406$ \\
Leaflets & $r .198$ & $r .256^{*}$ & $r .154$ & $r .102$ \\
Magazines & $r .460^{*}$ & $r .369^{*}$ & $r .136$ & $r .396$ \\
Top shows & $r .051$ & $r-.067$ & $r .056$ & $r .017$ \\
Opinion leaders & $r-.115$ & $r .097$ & $r-.217$ & $r-.074$ \\
Farm and home visits & $r-.161$ & $r .051$ & $r-.185$ & $r-.009$ \\
Method demonstration & $r .312^{*}$ & $r-.090$ & $r-.046$ & $r-173$ \\
Result demonstration & $r .344^{*}$ & $r .113$ & $r-.175$ & $r .232^{*}$ \\
\hline
\end{tabular}




\section{CONCLUSION}

The findings of this study revealed that most farmers received their farm information through mediated and professional inter-personal methods. The results also showed that radio $(\bar{x}=3.40)$ and fellow farmers $(\bar{x}=3.40)$ were perceived as the most appropriate sources used in disseminating agricultural information, while extension agents $(\bar{x}=3.37)$, radio $(\bar{x}=3.34)$ and television $(\bar{x}=3.16)$ were perceived as the most reliable information sources by the farmers. Major constraints to the use of these channels include illiteracy $(\bar{x}=3.97)$, unavailability of the information source $(\bar{x}=3.94)$, lack of access to information sources $(\bar{x}=3.39)$, and inappropriate scheduling of programme $(\bar{x}=3.89)$ among others. Further analysis of the results showed positive significant relationships between educational attainment and use of professional information sources; farmers' age and use of various information sources; household size and professional mass media sources as well as farming experience and use of various professional information sources.

Based on the major findings, the following recommendations were made:

1 Government should assist farmers in the area of sponsoring adult education so that farmers can make use of different sources of agricultural information effectively.

2 The use of internet is very fast and has a wider coverage thus pointing to the need for the provision of enabling environment for such facilities to thrive in rural areas for effective usage by the farmers and extension agents.

\section{REFERENCES}

Agwu, A. E. and Chah, J. M. (2007). Access and utilization of modern information communication technologies among extension personnel in Benue State of Nigeria. In Madukwe, M. C (Ed.). Agricultural Extension and the Challenges of the Millennium Development Goals (MDGs). Proceedings of the $12^{\text {th }}$ Annual Conference of the Agricultural Extension Society of Nigeria (AESON). Maiduguri, $4^{\text {th }}-7^{\text {th }}$ July 2007. pp $7-$ 21.

Agwu, A. E., Ekwueme, J. N. and Anyanwu, A. C. (2008). Adoption of improved agricultural technologies disseminated via radio farmer programme by farmers in Enugu State, Nigeria. African Journal of Biotechnology. Vol. 7 (9), pp. 1277 - 1286.

Anyanwu, A. C., Agwu, A. E. and Umeweni, C. A. (2002). Sources of agricultural information used by women farmers in Orumba Anambra State, Nigeria. ASSET: An International Journal. (ASSET Series A.). Vol. 2. No. 1 pp. 97-104.

Baron, S. (2002). Introduction to Mass Communication: Media Literacy and Culture. Boston USA: McGraw Hill Publishers.

Ekumankama, O.O (2000). Farmers' level of satisfaction with formal agricultural information source in Umuahia, Abia state, Nigeria. Journal of sustainable Agriculture and Environment. Micheal Okpara, University of Agriculture, Umudike. 2(2); Pp. 257 - 263.

Ekumankama, O.O and Nwankwo, G. (2002). Radio farm broadcast: A study of adoption of agricultural innovations in Umuahia zone, Abia State. Journal of Agricultural Extension. Vol. 6. Pp. $17-23$.

Foo. Chow-kam (1980). An Analysis of Nutrition Information source Use and Evaluation. M. Sc. Thesis. lowa State University Ames. Iowa. 


\section{Journal of Agricultural Extension}

\section{Vol. 13 (1) June, 2009}

Mohammed and Wanaso, 1993, Analysis of sources of farm Information: A case study of Farmers in the Western zone of Plateau State Agricultural Development project. The Nigerian Journal of Rural Extension and Development Vol. 1.pp. 49 - 55.

Mugabe J. O. (2003), Agricultural Biotechnology in Africa: Building public confidence and scientific capacity for food production. Annual Lectures (2002); published for United Nations. University - Institute for National resources in Africa (UMV - INRA) and UNE CA, Addis Ababa, Ethiopia $34 \mathrm{Pp}$.

Omenesa, Z. E. (1997). Rural agricultural radio in Nigeria: an overview of the National Agricultural Extension and Research Liaison Services (NAERLS) farm broadcast. Journal of Agricultural Extension. Vol. 1 pp $74-81$.

Omokhude C. A. (1999). A study of various agencies communicating agricultural information among selected farmers in Owan East Local Government Area of Edo State. Agricultural Extension Research and Development in Nigeria Proceedings of the $5^{\text {th }}$ Annual National Conference of the Agricultural Extension Society of Nigeria, (AESON) Pp. 99.

Patel A. U. and Anthonio Q. B. O (1971). An analysis of selected factors that influence the adoption of improved practices among tobacco farmers in the western states. The Nigerian Agricultural Journal .Vol. 8, No. 2. (1971) Pp 123 - 131.

World Bank (1990). World Development Report. Washington, D.C.

Yahaya, M.K. and Olayide, B. R. (2002). Effectiveness of contact Farmers strategy in Oyo State ADP. Administrative Lessons for Poverty Alleviation in Agricultural technology Transfer. Proceedings of the $6^{\text {th }}$ Annual National Conference of the Agricultural Extension Society of Nigeria (AESON), $10^{\text {th }}-12^{\text {th }}$ April. Pp $247-253$. 